\title{
Anorexia Nervosa and First-Person Perspective: Altruism, Family System, and Body Experience
}

\author{
Jérôme Englebert ${ }^{\mathrm{a}, \mathrm{b}}$ Valérie Follet ${ }^{\mathrm{a}}$ Caroline Valentiny ${ }^{\mathrm{a}}$

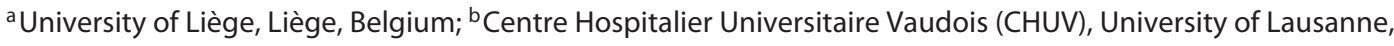 \\ Lausanne, Switzerland
}

(C) Free Author
Copy - for per-
sonal use only

ANY DISTRIBUTION OF THIS ARTICLE WITHOUT WRITTEN CONSENT FROM S. KARGER AG, BASEL IS A VIOLATION OF THE COPYRIGHT.

Written permission to distribute the PDF will be granted against payment of a permission fee, which is based on the number of accesses required. Please contact permission@karger.com

\section{Keywords}

Anorexia nervosa - Eating disorder - Body experience . Phenomenology · Psychopathology

\begin{abstract}
Based on the case study of Jeanne, the objective of this article is to study patterns of specific subjectivity in anorexic subjects. We seek to identify, in a first-person perspective, the core vulnerability features of anorexic existence, beyond the dimension of food alone. The identification of a psychopathological structure results in a better understanding of Jeanne's clinical situation and helps formulate psychotherapeutic and prophylactic recommendations. We suggest that so-called "denial" is a psychological mechanism that should be reconsidered. Denial is not a mechanism pertaining to anorexic subjects alone, but is also a process encountered both in the patient's family and in the therapeutic environment. Anorexic denial is based on anosognosia and the refusal to see one's own thinness, while other people's denial consists in a widespread inability to perceive the altruism and intersubjective problematic on which the existence of an anorexic subject fundamentally depends.
\end{abstract}

(c) 2017 S. Karger AG, Basel
(C) 2017 S. Karger AG, Basel

\section{Introduction}

The distinction between first-person and third-person perspectives constitutes a recent and decisive contribution of phenomenological philosophy to psychopathology $[1,2]$. Third-person perspective, which is used in the latest versions of the DSM or in evidence-based medicine, involves the attribution, from an external position, of clinical signs that have little to do with the perception expressed by the patient. The classic examples of these signs are schizophrenic delusion and hallucination. Those symptoms underline the difficulties experienced by the subject to identify himself as affected by the disorder (anosognosia). This point is considered a priority therapeutic target by dominant models.

Consideration of first-person perspective is the opposite process, focusing attention on subjective experience expressed by the patient. In schizophrenia again, what patients verbalize is "loss of natural self-evidence," "psychopathology of common sense," or "diminished sense of self" [2-5]. Those clinical signs, as they reveal the experience of the self, become the structuring psychopathological element and highlight a schizophrenic way of beingin-the-world.

\section{KARGER}

E-Mail karger@karger.com

www.karger.com/psp
Jérôme Englebert, $\mathrm{PhD}$

Department of Psychology, University of Liège

Bât. B33 Quartier Agora, Place des Orateurs 1

$\mathrm{BE}-4000$ Liège (Belgium)

E-Mail jerome.englebert@ulg.ac.be 
This paper aims to bring about this passage towards first-person perspective in an attempt to better understand the subjects affected by anorexia nervosa. We start from the hypothesis of Demaret [6], which suggests, in a somewhat disconcerting way, to not focus primarily on the purely medical angle related to weight loss and refusal to eat. This model uncovers the adaptive components of the disorder and resonates with the words of anorexic patients, who often do not perceive their thinness due to the well-known mechanism of denial. In first-person perspective - if we hand it over to the subject - anorexic anosognosia and the morbid tendency to deprive oneself of food at the risk of threatening one's life reveal a need (sometimes excessive) to take care of others, to feed them, but also excessive self-consciousness. The emotional and body investment in relationships is often seen as unsatisfying, even as being the driving force of uneasiness.

Actually, there are two tendencies which reinforce each other. On the one hand, anorexic behaviour could be the legacy of altruistic behaviour - probably unintentional or at least not stemming from a conscious intent - dating back to our ancestors and still observable in the animal reign - among social animals whose young females deprive themselves of food while actively taking part in the search for food for other members of the group (with a particular interest in the youngest ones). This behaviour, thanks to its outstandingly adaptive aspect for survival of groups, would have remained through evolution and ended up in our time among people with a particular interest in others. On the other hand, as it appears in anorexic people's own words, they attach fundamental importance to others' glaze, to what this glaze can imply in the definition of their own identity, in their feeling of legitimacy. These two tendencies have in common the central place held by relationships to others intersubjectivity - in psychological as well as behavioural functioning. Although it is not surprising that these two tendencies are expressed within the same psychopathological structure, we note a centrifugal motion - revealing the altruistic leaning - and a centripetal one - pointing out a disposition to autoconservation through others' point of view. The complex relationship between the anorexic subject and others probably lies in this double polarity.

This questioning of the omniscient vision of the medical leads to criticism of the domination power that comes with third-person perspective. It turns out to be a relevant psychotherapeutic tool. It desacralizes the anosognosia issue, questions the denial (this mechanism also becomes that of the family and friends of the anorexic person, who are not able to perceive the altruistic overinvestment), and opens the door to an intersubjective, co-constructed perspective. We propose, through this paper, to take interest in anorexic subjectivity starting from the analysis of the clinical case of a young female patient.

\section{Clinical Case}

Jeanne is 24 years of age and has been suffering from anorexia for 3 years. Her clinical picture is quite classic: weight loss, bulimia phases with vomiting, amenorrhea, nonexistent sex life and specific phobias, paradoxical hyperactivity (college student, high-level violinist, going scuba diving, and baby-sitting), and paradoxical interest in food (excellent cook, loves feeding other members of her family, and contributes to a blog dedicated to cooking). She confesses being now able to recognize her thinness in the mirror (denial was part of the clinical picture during her first months of illness). Jeanne explains that the way other people look at her is quite trying. She mentions a sense of shame based on the impossibility to know what others think about her and what exactly they see in her.

Jeanne recalls an emblematic episode of her existence before the disorder: "I'm in the kitchen, I've just finished cooking. My brother wants to serve the meal and I've got the feeling he is trying to take over the meal I've cooked."

Jeanne clarifies that she knows, however, that this feeling of usurpation is wrong, but she says she cannot stop thinking about it. She explains afterwards that she feels an awkwardness around the table (which is composed of her brother, her father, and her mother): "I'm still standing and keep serving the meal even though the plates are all abundantly filled. But I can't do anything else. Each of them, after having started to eat, pretend they don't see my inability to stop, tell me to sit and eat with them. I fake not hearing them, until my father, exasperated by an attitude which occurs at almost every meal, gets angry. I can't stand it and live this scene as a non-recognition of all I've done, of all the energy I've spent preparing the meal, I experience it as a non-recognition of who I am."

This story is emblematic of the anorexic impasse and failure to be understood. A network of crossed interpretations takes place between a young woman who does not feel understood and recognized in the eyes of her relatives, who themselves seem caught in an apparent denial of the disorder and a systematic refusal to evoke it. We can also observe that her relatives do not feel understood by the young woman and that the family also expresses a denial mechanism with regard to Jeanne's food altruism and concern about her family.

\section{Altruism as Adaptive Dimension}

Demaret $[6,7]$ proposes to identify group behaviour as one of the structuring elements of anorexic experience, especially altruistic conducts. He suggests not focusing as a priority on the purely medical aspects related to weight
2
Psychopathology DOI: $10.1159 / 000485629$
Englebert/Follet/Valentiny 
loss. This symptom is the most visible and worrying because refusal to eat, with no organic cause, may lead the subject to a very important state of slimming and even, in the most extreme cases, to death. However, if we go back to the difference between first-person and third-person perspectives, the symptom of refusing to eat, when we listen to anorexic patients - in this case Jeanne - is often minimized or refuted (that is the denial mechanism proposed by psychoanalysis, or the anosognosia proposed by cognitive psychology).

Demaret precisely considers it essential to take interest in other signs, often seen as secondary but formally associated with the anorexic picture and often brought up by patients. He notes the following: the usual absence of depression and negation of the skinny state, anosognosia, preservation of an important physical and mental activity, amenorrhea (which can be the consequence of undernutrition but occurs sometimes before that), female predominance of this disorder, episodes of bulimia, vomiting, and food altruism.

The paradox, often observed but rarely explained, of the deep interest in food is particularly interesting: anorexic patients usually have great knowledge of nutrition science, seek to feed others, and cook for their friends and relatives (that they sometimes seem to "force-feed"), steal food and conceal it in hiding places, often seem obsessed with food and never stop talking about it, and may present paradoxical phases of overeating (bulimia). A second paradoxical dimension of the disorder is typical hyperactivity. Those young girls whose appearance is weak and fragile often take upon themselves an impressive and permanent physical and intellectual activity.

They also seem particularly resistant to infectious diseases, as if they were immune [6] - except when the state of slimming becomes too severe and causes serious metabolic troubles. When the condition does not get blown out of proportion, we observe that anorexic people possess astonishing adaptive capacity to their environment ${ }^{1}$.

A behaviour of particular interest for Demaret is food altruism, which he considers the most fundamental component of the syndrome. To understand the functional dimension of this tendency to feed others, we must keep in mind that the adaptive value of behaviours is not solely directed at the individual, but extends to the group to which he or she is related. An individual who ingests very little food, remains active and resistant while presenting an "obsession" for food - which facilitates its search - and wishes to feed other members of the group presents a considerable advantage for one's belonging group. This behaviour particularly benefits the children of the group,

Anorexia Nervosa and First-Person

Perspective who require a great deal of attention and depend on others to feed themselves. Vomiting or regurgitating are, by the way, very widespread feeding modes in the animal world and in many human societies [6]. This taking care of children leads to a new paradoxical dimension of anorexia. While they are biologically unable to procreate (amenorrhea) and are often phobic to the idea, anorexic people present a great interest in children. They are or would like to be babysitters, in charge of youth clubs, childcare workers, paediatric nurses, speech therapists, educators, teachers, etc.

All of these elements allow us to generalize the altruism notion, which exceeds the food sphere. However, we can clarify that, in the line of psychoanalytic interpretation, understanding of prosocial anorexic behaviour has to be interpreted as an essential psychodynamic defence mechanism [14-16]. Altruistic care, sometimes resulting in force feeding, can "hide" an unconscious aggressive relationship to other. Feeding others is also controlling them in a very efficient way, and making them dependent on oneself. It is therefore interesting to keep in mind that this phenomenologically observed paradoxical altruistic behaviour (about feeding, but also generalized) can point out a more ambiguous relationship to others, made of hetero-control, anger, and even aggressiveness $[14,15]$. Besides, not feeding oneself (or very little) suggests another form of intersubjective but also subjective command and makes it impossible for others to feed him or her (anorexic patients often hate receiving food or eating in anybody's presence). Anorexic behaviour makes it impossible for another person to be in a position of command like the anorexic person. Another

\footnotetext{
1 We wish to stress in this footnote the notable literature of evolutionary psychiatry which grants an important place to anorexia and eating disorders. Refusing to eat, which seems to go against an adaptive logic, may be recontextualized in extreme conditions like famine [8-10]. The anorexic person manages to maintain vitality and energy in his/her search for new resources despite the little nutritional intake. Guisinger [11] observes that the anorexic person suffers a lesser weakening in the face of food deprivation and therefore is able to keep functioning in an adapted way in the case of undernutrition. The status of sexuality and reproductive potential is also evoked. The anorexic person's reproductive potential may be suppressed via amenorrhea when conditions are bad $[9,12]$, or else this potential may be suppressed by a dominant female who attempts to eliminate a rival from the "breeding race" by pushing female teenagers to starve themselves, thus leading to amenorrhea $[8,13]$. Stevens and Price [10] also approach the disorder from the "social ranking theory" point of view, proposing to consider eating disorders as a sort of remainder of class struggle. According to times and societies, either thinness or excess weight is seen as a sign of high social status. In our societies where resources are relatively abundant and where less privileged persons have access to food high in fats and sugars, thinness is valued and understood as a proof of willpower and body control.
} 
way of developing this notion of altruism - of which we have already pointed out the centrifugal-altruism/centripetal-consideration double polarity - is to understand it from the angle of gift and counter-gift developed in the anthropology of Mauss [17]. According to the anthropologist, the structure of social bond relies on a givereceive-render principle. It seems interesting thinking that the anorexic person lives this dimension of social bond in a distended, unstable way, seeking by turns to overinvest gift or counter-gift without reaching a reciprocal relationship which could allow a balanced and stable intersubjectivity.

At the same time as the identification of these behaviours, Demaret [6] resorts to a clarifying analogy with a corresponding animal mode. He finds, in the reports of Goodall [18] about the behaviour of female chimpanzees when they take interest in their mother's or sister's newborn, troubling similarities. They assume the role of educators and propose a form of prosocial behaviour learning. Those female primates have no offspring of their own and therefore raise a youth who is not theirs but is part of their close environment, which is not the case of Jeanne, but many anorexia cases are triggered among young adults whose parents welcome a new child. An analogical analysis allows us to assume a junction between this "helpers at the nest" animal behaviour and the anorexic behaviour; the analogy with the animal world helps us to understand the characteristic relationship between anorexic people and their close family system in a different light.

A link between ethology and phenomenology may seem, at first, simple to establish. Indeed, in both approaches, it is about meeting a phenomenon while putting aside, insofar as possible, one's theoretical a priori interpretations, in order to be able to get surprised and to not orientate the way we look at this phenomenon. However, if we linger over the first-person perspective as a phenomenological approach to a situation, it becomes more difficult to understand at once the link with ethology. Indeed, because animals do not speak, it is impossible to gather their opinion about their situation or feelings, and observations may, at first glance, seem more specific of a third-person perspective. Nonetheless, a slight difference stands in the adopted point of view with respect to the animal's world (Umwelt) [19]. If we place ourselves in an understanding process of the situation as it is lived by the animal, considering the meaning this world can have for him rather than transmitting our own interpretations and references, we get closer to first- than third-person perspective.

\section{Anorexic Psychopathology and Body Experience}

Phenomenological analysis in psychopathology focuses on understanding individual subjectivity and, therefore, falls within a first-person perspective. Many works of this tradition have come to link anorexic psychopathology with complex alterity and "intercorporeity" processes [20-28]. According to a traditional proposition of phenomenology, we can distinguish two types of body experience. Leib is the body as experienced, that is, direct and intuitive body experience lived from the inside and in first-person by the subject. It corresponds to what the subject is for himself, as a spatiotemporal being, embodied in the world. Körper, or body as an object, is the explicitly perceived body, seen from the outside, in thirdperson. Leib is emotional and evokes transcendence of the self, whereas Körper is devitalized. One is moved by intentionality and subjectivity, the other comes down to an objective mechanism. Körper is the body which can be manipulated, for example, the one handled by a surgeon when he operates or the one studied by the anatomist, while Leib is the body which manipulates the world, the one the phenomenologist addresses as well as the clinician. In the practice of psychiatry or in many cognitive psychology perspectives, practitioners deal with Körper with regard to medication or cognitive function remediation practices.

This first contribution is useful to our understanding of anorexic body experience because it demonstrates that it is possible to evoke body existence beyond the simple materiality of this body, or beyond its simple representation $[21,28]$, and consequently beyond its state of slimness. An anorexic-lived body cannot be reduced to the marks of the disease. The body experience of the anorexic person transcends the extreme thinness of his/her arms. His/her body is moved by intentionality, in other words by the tendency of the consciousness to go beyond itself and to burst into the world. However, as Bowden [20] and Gaete and Fuchs [28] underline it, the expression of the anorexic-lived body is obviously troubled. The anorexic person suffers from disordered bodily experience in the sense of being cut off from a range of sensations. She does not inhabit her body in an evident way and is only imperfectly "in" it.

In order to highlight this pathological relationship with bodily experience, Bowden [20] discusses the body as subject/objet, based on the works of Merleau-Ponty [29]. The latter studies the fact that the body is endowed with a double sensation which consists in being able to touch (active dimension) and to be touched (passive di-
4

Psychopathology

DOI: $10.1159 / 000485629$
Englebert/Follet/Valentiny 
mension). Merleau-Ponty [29] exemplifies this with touching one's right hand with one's left hand: "The first is an intersecting of bones, muscles, and flesh compressed into a point of space; the second shoots across space to reveal the external object in its place" $[29$, p. 94]. But the philosopher clarifies there are mixed situations, revealing double sensations: "So when I press my two hands together, it is not a question of two sensations that I could feel together, as when we perceive two objects juxtaposed, but rather of an ambiguous organization where the two hands can alternate between the functions of 'touching' and 'touched'" [29, p. 95].

However, this intersecting is also a matter of contact with external objects, with the world. For example, when the pianist's hand meets the ivory of the piano key, it pushes on the latter but, simultaneously, deals with an opposite pressure generated by the mechanism of the piano strings. All the power, the accuracy, and the virtuosity of the sonority (and the personal colouration given by the artist) rest on this subtle alchemy of combined touching and being touched.

The touching-touched body also has to come to terms with other bodies - which also respond to this dialectic. It brings us closer to the anorexic experience. The body, in the social jungle, is at the same time an active subject perceiving the neighbouring world and a passive object able to be perceived. The structural problematic of anorexic experience precisely takes root in the comparing with others' bodies. At some point, Jeanne confided in us that if she were to live on a desert island, there would be nobody to speak about anorexia and she would never suffer from it; let us remember that her abilities for finding food would probably allow her, more than others, to adapt and survive in such a situation. She also expressed a recurrent dream in which she was in a room with walls made of two-way mirrors. She knew that she was being observed, yet she could not see the people observing her (which is an unsolvable intercorporeal paradox that only dreams can withstand).

Our philosophico-clinical reflection finds in the work of Sartre [30] the most accomplished model regarding body experience and experience of others. For the latter, this problematic of "being seen by others," far from being secondary, is a founding experience of identity process: "I exist for myself as a body known by the Other. [...] The shock of the encounter with the Other is for me a revelation in emptiness of the existence of my body outside as an in-itself for the Other" [30, pp. 351-352]. Our connection to others is therefore necessary for the achievement of our body anchorage in the world and for our faculty to

Anorexia Nervosa and First-Person Perspective live inside our own body. The other is the only one able to accomplish a function which is fundamental to us: "to see ourselves as we are" [30, p. 354]. Leaning on this analysis, Bowden [20] but also Stanghellini et al. [26, 27] suggest there is, in the anorexic person, an imbalance between the perceiving-subject-body and the perceived-object-body, the latter taking a much too decisive place. Under the eyes of others, the anorexic person loses his/ her capacities for body subjectivity. Intentionality escapes him/her and begins to depend on the watching body. In this context, Jeanne develops an exacerbated consciousness of her every gesture. How others see and look at her obsess her. For example, she says that the central element of her relationship with her father is "his eyes, the heaviness of his glaze judging me, judging who I am."

According to Sartre [30], the feeling associated with others' look towards one's own body is the emotion of shame. He takes the example of a man who is looking through a keyhole. Totally absorbed and lost in the world - he is only eyes, not a body being watched - he suddenly becomes aware of someone's presence behind him. His lived-body-for-others emerges to his consciousness through the discovery of another observing him. The spy becomes the one being spied on, and the predominant emotion is the shame of an individual who feels deprived of his role as an active subject and becomes reduced to being subjected to others. Bowden [20] suggests a parallel between this feeling of "relational shame" and the anorexic body experience. The intrusion of the other's look is permanent in the anorexic person.

This "phenomenology of anorexia," thanks to the consideration of body experience and its relational dimension, enables us to take the focus away from the obvious refusal to eat. From this point of view, in order to understand Jeanne's problematic, we have to glimpse over this dominant symptom. We need to read between the lines of the obvious facts. This proposal runs counter to evidence-based medicine (or completes it) since the clinician precisely has to get "out of step" with scientific attitude. Merleau-Ponty [29] reminds us that the subject is not "the result or the intertwining of multiple causalities that determine [his] body or [his] 'psyche'; [He] cannot think of [himself] as a part of the world, like the simple object of biology, psychology, and sociology; [He] cannot enclose [himself] within the universe of science [...]. The entire universe of science is constructed upon the lived world, and if we wish to think science rigorously, to appreciate precisely its sense and its scope, we must first awaken that experience of the world of which science is the second-order expression" [29, p. xxi, xxii]. From this

Psychopathology

DOI: $10.1159 / 000485629$ 
point of view, the ethological approach of Demaret [6] meets phenomenology. Through their common methodology of observation, hidden adaptive significations emerge from one when the other reveals states of intersubjectivity.

\section{Conclusion: Anorexia and First-Person Perspective}

All of these analyses suggest that the fundamental problematic of anorexia is an issue of intersubjectivity, integrating altruism (related to food or more global) and the process of intercorporeality. To complete this consideration of first-person perspective, we need to go back to Jeanne's situation and seek to characterize the emotion that connects our patient to her family. She confided in us several times of having cooked for all her family and feeling poorly understood, even usurped. After proposing to leave the food symptomatology out of our reflection, it seems interesting to come back to it in its social dimension. It will help us to wonder about what feeding represents beyond the strictly nutritive dimension. Indeed, feeding turns out to be a powerful emotional conveyor [32]. Comfort foods are major emotional components that combine cultural elements and family features. The country and area where one lives possess their own specialities and each family gives unique meaning to those recipes. Finally, within the family, new generations will never achieve an identical replication of the delicacy of the grandmother's madeleine. The aesthetics of Proust [31] remind us that eating is an essential biological need upon which social signification gets propped up, whereby common sense is passed intuitively. Jeanne, and it is probably a central characteristic of the anorexic being-in-theworld, overinvests this emotional flexion of the "eating dinner." She is the guarantor of an emotional play of her family's gastronomic traditions. Relationship to others, for others, takes up all the room for her. The anorexic person has difficulty finding his/her place on the continuum between emotional need and eating need that the meal represents. Food may, consequently, lose all of its nutritional value (at least for him/her), becoming a "natural fetish," to quote Sartre [32], allowing for emotions to circulate.

Consequently, it is inconceivable for the anorexic person to condone that "refusal to eat" is what characterizes his/her trouble, since it is quite the opposite. Food is even rather fundamental since it opens, for the anorexic person, the path to others. A therapy based on the epistemology of the third-person perspective, which considers that what needs to be treated is what obviously stands out (in other words refusal to eat), is actually at the antipodes of the anorexic person's subjectivity. We understand why Jeanne claims to be traumatized by having been hospitalized in a psychiatric environment which did not allow her to go back home and see her relatives during the weekend if she had not put on enough weight. This therapeutic position is in contradiction with what the patient knows about her trouble. It reproduces the attitude of Jeanne's family members who are concerned with the evidence of her refusal to eat. Our contribution tends to demonstrate that the denial mechanism is not only experienced by the anorexic patient and her anosognosia, but also conveys the inability of others to perceive her altruism and her intersubjective problematic.

The therapeutic proposal of our contribution consists in moving the focus to the problematic of unbalanced relationship to others (being too dependent or behaving as if the other was dependant on oneself). Placing this relationship to others in a larger context (a family, group, or society perspective), which calls upon adaptive mechanisms inherited from our ancestors through phylogenesis, also allows one to step out of a point of view only focused on the anorexic person (even on the relationship to her mother, in certain approaches), with all it can entail in terms of shaming or stigmatization. As for the firstperson perspective, it offers the anorexic person the possibility to appropriate the right to define who she really is, to not be subjected to the identity she is saddled with by other's judgement, including the medical one, however benevolent the underlying intentions.

\footnotetext{
References $\quad 1$ Zahavi D: Subjectivity and Selfhood: Investigating the First-Person Perspective. London, MIT Press, 2005.

2 Parnas J, Sass L, Zahavi D: Rediscovering psychopathology: the epistemology and phenomenology of the psychiatric object. Schizophr Bull 2013;39:270-277.

3 Blankenburg W: Der Verlust der natürlichen Selbstverständlichkeit: Ein Beitrag zur Psychopathologie symptomarmer Schizophrenien. Stuttgart, Enke, 1971.

4 Stanghellini G: Disembodied Spirits and Deanimated Bodies: The Psychopathology of Common Sense. Oxford, Oxford University Press, 2004.

5 Englebert J, Valentiny C: Schizophrénie, conscience de soi, intersubjectivité: Essai de psychopathologie phénoménologique en première personne. Brussels, De Boeck, 2017.
}

Englebert/Follet/Valentiny
Psychopathology
DOI: $10.1159 / 000485629$ 
6 Demaret A: Éthologie et psychiatrie, ed 2 (edited by Englebert J, Follet V). Brussels, Mardaga, 2014.

7 Englebert J, Follet V: Essai de psychopathologie éthologique; in Englebert J, Follet V (eds): Éthologie et psychiatrie. Brussels, Mardaga, 2014, pp 165-231.

8 Brüne M: Textbook of Evolutionary Psychiatry: The Origins of Psychopathology. Oxford, Oxford University Press, 2008.

9 McGuire MT, Troisi A: Darwinian Psychiatry. Oxford, Oxford University Press, 1998.

10 Stevens A, Price J: Evolutionary Psychiatry: A New Beginning, ed 2. London, Routledge, 2000.

11 Guisinger S: Adapted to flee famine: adding an evolutionary perspective on anorexia nervosa. Psychopathol Rev 2003;10:745-761.

12 Surbey MK: Anorexia nervosa, amenorrhea, and adaptation. Ethol Sociobiol 1987;8:4761.

13 Mealey L: Anorexia: a "losing" strategy? Hum Nat 2000;11:105-116.

14 Boris HN: The problem of anorexia nervosa. Int J Psychoanal 1984;63:315-322.

15 Stern JM: 'No entry', an invitation to intrude, or both? Reflections on a group of anorexic patients. Int J Psychoanal 2013;94:689-713.
16 Sollberger D: The inversion of the fall: on identity construction in anorexia nervosa. Psychopathology 2014;47:244-251.

17 Mauss M: The Gift: The Form and Reason for Exchange in Archaic Societies. New York, Norton, 2000.

18 Goodall J: New discoveries among Africa's chimpanzees. Natl Geogr Mag 1965;128:802831.

19 Von Uexküll J: Mondes animaux et monde humain. Paris, Denöel, 1965.

20 Bowden H: A phenomenological study of anorexia nervosa. Philos Psychiatr Psychol 2012;19:227-241

21 Jacobson K: The interpersonal expression of human spatiality: a phenomenological interpretation of anorexia nervosa. Chiasmi Int 2006;8:157-173.

22 Leder D: A disease of doubling. Philos Psychiatr Psychol 2013;20:93-96.

23 Legrand D: Object and others: diverting Heidegger to conceptualize anorexia. Philos Psychiatr Psychol 2012;19:243-246.
24 Legrand D, Taramasco C: Le paradoxe anorexique: quand le symptôme corporel s'adresse à l'autre. Evol Psychiatr (Paris) 2016;81: 309-320.

25 Stanghellini G: For an anthropology of eating disorders: a pornographic vision of the self. Eat Weight Disord 2005;10:21-27.

26 Stanghellini G, Castellini G, Brogna P, Faravelli $C$, Ricca V: Identity and eating disorders (IDEA): a questionnaire evaluating identity and embodiment in eating disorder patients. Psychopathology 2012;45:147-158.

27 Stanghellini G, Trisolini F, Castellini G, Ambrosini A, Faravelli C, Ricca V: Is feeling extraneous from one's own body a core vulnerability feature in eating disorders? Psychopathology 2015;48:18-24.

28 Gaete MI, Fuchs T: From body image to emotional bodily experience in eating disorders. J Phenomenol Psychol 2016;47:17-40.

29 Merleau-Ponty M: Phenomenology of Perception. New York, Routledge, 2012.

30 Sartre J-P: Being and Nothingness: A Phenomenological Essay on Ontology. New York, Pocket Books, 1978.

31 Proust M: Du côté de chez Swann. Paris, Gallimard, 1913.

32 Englebert J: Psychopathologie de l'homme en situation. Paris, Hermann, 2013.

\section{(C) Free Author Copy - for personal use only}

ANY DISTRIBUTION OF THIS ARTICLE WITHOUT WRITTEN CONSENT FROM S. KARGER AG, BASEL IS A VIOLATION OF THE COPYRIGHT. Written permission to distribute the PDF will be granted against payment of a permission fee, which is based on the number of accesses required. Please contact permission@karger.com

Anorexia Nervosa and First-Person

Perspective
Psychopathology

DOI: $10.1159 / 000485629$

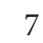

